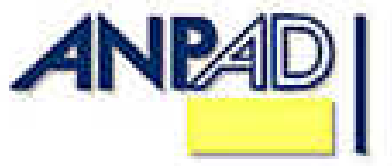

Disponível em

http://www.anpad.org.br/rac

RAC, Curitiba, v. 15, n. 5,

pp. 955-968, Set./Out. 2011

Casos de Ensino em Administração:

\title{
Estratégia de Crescimento no Mercado Brasileiro de Cursos Pré- Vestibular: Caso Sistema Elite de Ensino
}

\section{Growth Strategy in the Brazilian Market for College Preparation Courses: the Case of Sistema Elite de Ensino}

Oscar Camilo Silva Evangelista*

E-mail: ocsevangelista@gmail.com Universidade Federal do Rio de Janeiro - COPPEAD/UFRJ Rio de Janeiro, RJ, Brasil.

Cristiane Pizzutti dos Santos

E-mail: cpsantos@ea.ufrgs.br Universidade Federal do Rio Grande do Sul - UFRGS

Porto Alegre, RS, Brasil.

* Endereço: Oscar Camilo Silva Evangelista

Rua Pascoal Lemme, 355, Ilha do Fundão, Rio de Janeiro/RJ, 21941-918.

Copyright (C) 2011 RAC. Todos os direitos, até mesmo de tradução, são reservados. É permitido citar parte de artigos sem autorização prévia, desde que seja identificada a fonte. 


\section{Introdução}

"Não há caminho fácil da terra às estrelas".

Sêneca

É tarde da noite, mas as luzes no interior do prédio indicam que alguém ainda está no local. Alberto, em sua sala, desliga o telefone e mira o vazio. Sua presença é constante na unidade de Porto Alegre, todos os dias, o dia todo - afora as ausências ocasionadas por suas aulas como aluno do curso de mestrado em Administração. Os estudantes do curso pré-vestibular já foram embora, os professores idem. No recinto, somente ele e o dilema que o acompanha há algum tempo, dilema este que aparece mais forte, sempre que Alberto conversa, como aconteceu há pouco, com algum de seus sócios justamente porque é a perenidade de sua empresa que está em jogo.

\section{A História de Alberto}

Desde cedo, Alberto sempre teve paixão por desafios. Ao terminar o ensino médio, ao contrário da maioria de seus colegas, que foi para o mercado de trabalho ou para uma faculdade local, ele decidiu enfrentar seu primeiro grande obstáculo: mudar-se para outro Estado, a fim de fazer um curso superior de primeira qualidade. Assim, saiu de Rio Grande (RS), sua cidade natal, para ingressar no Instituto Tecnológico de Aeronáutica (ITA), tido como o melhor curso de engenharia do país. Ao se formar, em 1993, diante de diversas alternativas de emprego, abdicou da carreira técnica para trabalhar no mercado financeiro.

Após um período de dois anos, resolveu enfrentar nova mudança em sua vida: deixou seu cargo como analista financeiro de um banco de investimentos e foi contratado como trainee de uma multinacional de bens de consumo. Novamente, contrariando as expectativas mais conservadoras, optou por deixar São Paulo, grande vitrine profissional para executivos, e candidatou-se a uma vaga em uma das fábricas da empresa situada na região Norte.

Depois de assumir o cargo de gerente de produção da fábrica em questão, Alberto passou por uma situação aparentemente corriqueira, mas que começaria a definir os rumos de seu futuro. Ao ser interpelado por um amigo, cujo sobrinho encontrava dificuldades em sua preparação para o vestibular, ele percebeu duas coisas: primeiro, os adolescentes com idade para ingressar na universidade estavam saindo do ensino médio com sérias deficiências em sua formação educacional, o que acarretava novos desafios nas dificuldades enfrentadas por esses adolescentes nos concursos vestibulares; segundo - e muito provavelmente a principal causa das deficiências dos alunos - os próprios professores apresentavam deformações em seu conhecimento específico, transmitindo ensinamentos errôneos aos estudantes.

Assim, como maneira de passar o tempo, quase como um hobby, Alberto e seu amigo Giordano começaram, em setembro de 1996, a ministrar aulas para preparação pré-vestibular. Instalaram um quadro negro no apartamento de Alberto, imprimiram certa quantidade de panfletos e contrataram algumas pessoas para fazer a distribuição destes. O grande chamariz deste material constituía-se na seguinte frase: Aulas Grátis de Matemática e Física! Com esse apelo, conseguiram, desde o início, atingir a lotação máxima da sala de aula, lecionando para cerca de quarenta alunos. Apesar da alta rotatividade dos estudantes, aqueles mais assíduos atingiram resultados expressivos, com aprovação em vestibulares bastante concorridos. Com isso, estes primeiros frutos deram ânimo aos dois novos professores, que enxergaram uma oportunidade interessante para a entrada neste mercado. 


\section{A Gênese de um Curso Pré-Vestibular}

Com o sucesso dessa primeira iniciativa, Alberto e Giordano identificaram a existência de uma demanda relativa à preparação pré-vestibular na região, e decidiram iniciar um curso preparatório na cidade de Belém (PA). Surge, assim no início de 1997, o Cursinho Titular. Por conta da propaganda boca a boca gerada, a divulgação da nova empreitada obteve resultados acima do esperado. Mesmo passando de aulas gratuitas para um curso pago, a procura foi muito grande; no início de 1997, havia por volta de 400 inscritos. Como a estrutura montada não possuía tal capacidade, foi aplicada uma prova, e os 100 melhores foram matriculados. Surgiu, então o primeiro revés: após a primeira semana de aula, não mais do que 30 alunos continuaram a frequentar as aulas! Com isso, os dois sócios perceberam que suas expectativas em relação ao conhecimento dos alunos estavam exageradamente elevadas, e precisaram adaptar a abordagem didática e ritmo das aulas para contemplar as deficiências estruturais de educação que os jovens apresentavam.

Porém, mesmo com o alto índice de desistência de alunos no início do curso, por conta do conteúdo denso e do ritmo árduo das aulas, os frutos colhidos no final do primeiro ano foram muito bons. Com a adaptação didática ocorrida ao longo do período letivo - sem abandonar a ideia original de preparação intensa para o vestibular - o Titular conseguiu manter os alunos até o final: a grande maioria obteve aprovação nas principais universidades públicas e particulares, dentro e fora do Pará (até mesmo nos grandes centros, onde a concorrência é mais acirrada e o nível de exigência consideravelmente maior). O alto índice de aprovação deu ao curso evidências concretas de qualidade, ao mesmo tempo que a divulgação boca a boca aumentava, atraindo novos interessados. Assim, o Titular começou a obter reconhecimento na região.

Em 1998, mil estudantes fizeram a prova para seleção e, com o aumento da estrutura, 400 alunos foram aprovados para matrícula. Com a contínua evolução na parte pedagógica, o nível de desistência caiu drasticamente, e o Titular passou a ter um número expressivo de jovens em suas salas de aula. Em paralelo, Alberto e Giordano descobriram iniciativas semelhantes às suas em outras partes do Brasil. Estimulados pelos preceitos de cooperação e eliminação de retrabalho, esses cursos isolados passaram a se comunicar e interagir entre si. Estabeleceu-se, então, o intercâmbio entre preparatórios pré-vestibular de três diferentes cidades: Recife, Rio de Janeiro e Belém. O intuito era compartilhar procedimentos e materiais (como, por exemplo, provas e exercícios), evitando que cada curso precisasse desenvolver todos os processos do início. Esboçava-se, dessa maneira, a primeira tentativa de aglutinar estas unidades isoladas em um mesmo sistema.

\section{O Sistema Elite de Ensino}

Os anos de 1998 e 1999 foram caracterizados por uma fase de crescimento e alinhamento. Ou seja, ao mesmo tempo que cada curso buscava seu desenvolvimento local, havia a preocupação de instituir uma padronização nacional. Houve maior aproximação entre os proprietários desses cursos, com a ocorrência frequente de reuniões presenciais. Nestes encontros, criaram-se procedimentos operacionais a serem adotados pelas unidades envolvidas; os responsáveis por cada área da organização (Operações, Marketing, Recursos Humanos, Finanças etc.) foram designados, e o nome da nova empresa foi definido. Surgia, assim, o Sistema Elite de Ensino.

Como todas as unidades eram relativamente novas, cada uma tratava de colher os frutos plantados em seus primeiros anos para estimular seu crescimento. Por exemplo, o antigo Curso Titular, agora com a marca Elite, angariava ganhos expressivos na sua região, tanto em resultados como em reconhecimento. Já em 1998, o Elite Belém aprova dez alunos no vestibular do ITA, de um total de 120 vagas - em um Estado sem histórico de aprovação nesta instituição. No mesmo ano, outro estudante conquista o primeiro lugar do Brasil no vestibular da Academia da Força Aérea (AFA), fato inédito no Pará. Em 1999, o Elite Belém, com um número consideravelmente menor de estudantes do 
que os concorrentes mais tradicionais, consegue maior aprovação absoluta em quantidade de alunos do que qualquer outro curso da cidade. Esses feitos aumentaram ainda mais a exposição do Elite na mídia, contribuindo para o crescimento do sistema e o fortalecimento da marca. As demais unidades seguiam pelo mesmo caminho, em ritmos de desenvolvimento menos ou mais acelerados.

Entretanto, nos anos seguintes, o crescimento do Sistema Elite passou por suas primeiras turbulências. Com a marca relativamente forte, os concorrentes tradicionais passaram a se incomodar, contra-atacando de maneira intensa - e, por vezes, desleal. Assim, cada unidade passou a dedicar a maior parte de seus esforços para a resolução de problemas regionais, buscando consolidar sua presença na cidade em que estava instalada. Como consequência, o crescimento voltado para o mercado local fez com que a integração nacional fosse deixada em segundo plano.

Outro obstáculo era o desequilíbrio entre as unidades. Com o sucesso da iniciativa, outros cursos espalhados pelo Brasil buscaram o apoio do Sistema Elite; porém, devido a características relativas ao mercado e à concorrência, alguns cursos cresceram muito mais do que outros. Com o aumento do número de alunos e a consequente expansão da estrutura - em algumas localidades, o foco em preparação pré-vestibular deu lugar à oferta também de ensino médio e fundamental - as maiores unidades voltaram sua energia e dedicação para as questões internas, diminuindo muito a cooperação. Assim, os estabelecimentos menores já não encontravam o mesmo apoio de outrora para se desenvolver. Além disso, o suporte para a abertura de novas unidades - principalmente em regiões mais distantes - ficou mais escasso, tornando a operação inicial destas mais complicada.

A padronização também não ocorreu como o esperado. Os procedimentos universais foram criados, mas não existiam mecanismos para garantir a sua adoção. Como a administração das unidades era totalmente autônoma, cada uma punha em prática os processos que mais interessavam, ignorando os demais. A utilização da marca é um bom exemplo neste quesito. Enquanto algumas unidades alteraram seus nomes, adotando a marca Elite, outros cursos preferiram manter suas identidades, por receio de perder o reconhecimento já conquistado no mercado. Assim, apesar de constituírem o mesmo sistema, os diversos estabelecimentos de ensino não partilhavam de uma identificação única perante o público, o que deixava as unidades menores mais vulneráveis em termos de identidade.

Essas dificuldades, aliadas a uma expansão desorganizada alimentada pelo otimismo e sucesso dos primeiros empreendimentos, levaram o Sistema Elite de Ensino a diversos acidentes de percurso, acarretando até mesmo no fechamento de algumas unidades em mercados mais turbulentos. Esta situação abalou a harmonia existente entre os dirigentes da organização, causando uma cisão entre dois grupos: um mais conservador, preocupado com as questões internas e buscando maior estruturação e padronização dos cursos já existentes; e outro mais agressivo, interessado no ambiente externo e tentando aproveitar as oportunidades de consolidação da marca, por meio da expansão para localidades onde o Sistema Elite não possuía presença.

O ímpeto e vigor da juventude, tão importantes para o sucesso inicial das operações, eram agora sobrepujados pela inexperiência e falta de maturidade dos jovens gestores. Muito foi discutido, mas nenhum plano de ação concreto foi posto em prática. Diante do impasse em relação aos rumos da organização, cada unidade continuou com seu desenvolvimento independente, voltado para as demandas locais, relegando o ideal inicial de cooperação ao papel de mero coadjuvante - apesar da existência de uma marca nacional.

\section{Uma Nova Tentativa de Integração}

O ano de 2003 trouxe possibilidades de mudanças tanto para Alberto quanto para o Sistema Elite de Ensino. Ao mesmo tempo que Alberto retornava para seu estado natal, com o objetivo de iniciar nova operação em Porto Alegre, outra oportunidade de integração entre as unidades batia à porta da organização, dessa vez por meio de uma parceria. 
Quando deixou Belém para se instalar em Porto Alegre, Alberto chegou com o intuito de abrir uma unidade do Sistema Elite no Sul do país, região que não contava com a presença da organização. Enquanto a nova empreitada dava seus primeiros passos, Alberto foi contatado pelo IESDE, empresa baseada em Curitiba e especializada na confecção de material didático. Convidado, junto com os outros sócios, a participar de uma reunião na sede do IESDE, Alberto descobriu que a empresa pretendia desenvolver uma linha de material didático premium, para ser utilizado em escolas e cursos com alto nível de exigência. Os resultados nacionais de aprovação do Elite, que a essa altura já estavam bem consolidados, não passaram despercebidos da empresa em questão, que enxergou ótima oportunidade de firmar uma parceria para a confecção deste novo material.

A proposta do IESDE contemplava o próprio investimento na marca Elite como forma de gerar maior visibilidade para o material desenvolvido. Esse investimento reanimou o espírito de cooperação entre as filiais, uma vez que existia a possibilidade de ganhos reais para todos. O trabalho de geração de conteúdo foi dividido por diversas unidades, que começaram a interagir em prol da coesão didática da iniciativa. Essa reaproximação reacendeu a centelha do ideal de integração do final da década de 1990, agora em torno de algo mais concreto: um material didático elaborado em conjunto, para ser adotado por toda a organização, e com a possibilidade de comercialização para outras empresas interessadas. Esse tipo de evidência física poderia ser um passo importante para atingir a unificação pretendida nos primeiros anos do sistema.

Porém esta nova tentativa também apresentou um grau elevado de dificuldade na implantação. Por conta das particularidades de cada região, onde cada vestibular é estruturado de uma maneira diferente, o conteúdo gerado por unidades distintas não foi bem aceito em âmbito nacional. Os responsáveis pela confecção do material muitas vezes entravam em conflito acerca dos tópicos a serem abordados, ou sobre que tipo de exercício deveria acompanhar o texto. Em paralelo, houve muitas críticas em relação à densidade do conteúdo, considerado complexo mesmo para os padrões de qualidade do Elite - característica que certamente inibiria a adoção desse material por escolas menos exigentes. Com tudo isso, algumas unidades ignoraram a existência do novo material, continuando a utilizar seus livros e apostilas originais, e frustrando novamente as pretensões de união nacional.

A abertura de novas unidades também gerou alguns problemas. Impulsionadas pela criação do Elite Porto Alegre e pelo lampejo de integração vislumbrado na parceria com o IESDE, algumas filiais foram abertas em cidades onde não havia presença do Elite. As novas unidades esperavam contar com o apoio de outras já estabelecidas para enfrentar as dificuldades inerentes ao início de nova operação; os cursos consolidados, entretanto, estavam mais voltados para sua estrutura interna, oferecendo pouco suporte aos recém-criados, e gerando muita insatisfação por parte dos menores.

Mais uma vez, a autonomia entre as unidades falou mais alto, e as particularidades e interesses locais foram priorizados em detrimento da coesão nacional. Esta nova desilusão, aliada aos transtornos causados pela primeira tentativa de integração, deixou marcas profundas na administração da organização. A consequência mais grave desta crise foi a decisão de interromper por completo a abertura de filiais em novas cidades. Assim, a partir de 2005, a expansão física do Sistema Elite de Ensino foi estancada.

\section{Cenário em 2009}

O Sistema Elite de Ensino é de propriedade de quatro sócios: Alberto, Giordano, Estevão e Nicolau. Está presente em dez cidades nas regiões Sul, Sudeste, Norte e Nordeste (Tabela 1); em algumas destas localidades - como no caso do Rio de Janeiro - existe mais de uma unidade dentro de uma mesma área geográfica. Na maioria das cidades, a marca Elite é utilizada como bandeira para designar as operações da organização. Entretanto, em alguns locais, ainda se mantêm as marcas próprias originais dos estabelecimentos. O caso mais atípico é o de Belo Horizonte, que incorporou o nome Elite à sua identidade original e utiliza os dois em conjunto. 
Tabela 1

Áreas de Operação do Sistema Elite de Ensino

\begin{tabular}{|c|c|c|c|c|c|}
\hline Cidade & $\begin{array}{l}\text { Ano de } \\
\text { Fundação }\end{array}$ & $\begin{array}{l}\text { Número de } \\
\text { Alunos }\end{array}$ & $\begin{array}{c}\text { Público-Alvo (Classe } \\
\text { Social) }\end{array}$ & Marca & $\begin{array}{l}\text { Material } \\
\text { Didático }\end{array}$ \\
\hline Belém (PA) & 1996 & 2.000 & $\begin{array}{l}\text { Primário: B } \\
\text { Secundário: C }\end{array}$ & Elite & Elite \\
\hline Recife (PE) & 1996 & 4.000 & $\begin{array}{l}\text { Primário: B } \\
\text { Secundário: A }\end{array}$ & Própria & Próprio \\
\hline Rio de Janeiro (RJ) & 1997 & 5.000 & $\begin{array}{l}\text { Primário: B } \\
\text { Secundário: A/C }\end{array}$ & Elite & Elite \\
\hline São Paulo (SP) & 1998 & 600 & $\begin{array}{l}\text { Primário: B } \\
\text { Secundário: A }\end{array}$ & Própria & Próprio \\
\hline Belo Horizonte (MG) & 1999 & 4.000 & $\begin{array}{l}\text { Primário: B } \\
\text { Secundário: A }\end{array}$ & Mista & Próprio \\
\hline Juiz de Fora (MG) & 1999 & 1.000 & $\begin{array}{l}\text { Primário: B } \\
\text { Secundário: A }\end{array}$ & Própria & Próprio \\
\hline Porto Alegre (RS) & 2003 & 150 & $\begin{array}{l}\text { Primário: A } \\
\text { Secundário: B }\end{array}$ & Elite & Elite \\
\hline Campinas (SP) & 2004 & 500 & Primário: A & Elite & Elite \\
\hline Curitiba (PR) & 2005 & 300 & $\begin{array}{l}\text { Primário: B } \\
\text { Secundário: A }\end{array}$ & Elite & Elite \\
\hline Ipatinga (MG) & 2009 & 200 & Primário: A & Elite & Elite \\
\hline
\end{tabular}

A organização mantém parcerias com duas empresas do ramo educacional: o IESDE, que confecciona material didático, e a Educandus, fornecedora de conteúdo interativo de apoio às aulas (CD-ROMs e vídeoaulas). Grande parte das unidades do Elite utiliza o material desses parceiros; porém, a exemplo da marca, em algumas cidades os cursos optam pela fabricação de material próprio.

A abertura de novas unidades continua restrita, e está condicionada ao envolvimento direto de pelo menos um dos quatro sócios na criação de uma potencial filial. Graças a essa possibilidade, após quatro anos de estagnação, um novo estabelecimento foi aberto em 2009, na cidade de Ipatinga (MG). Tal empreitada tem a participação de Alberto, que vislumbrou uma oportunidade na região em questão, carente de cursos preparatórios de alta qualidade.

\section{Serviços oferecidos}

Basicamente, o Sistema Elite de Ensino oferece cursos pré-vestibulares na modalidade extensiva, com duração de fevereiro a dezembro. Esses cursos, voltados para aprovação nos vestibulares mais concorridos do país, são ministrados em período integral, de segunda a sábado, e possuem, geralmente, quatro turmas, cada uma com um objetivo específico: uma com foco na preparação em ciências exatas (especialmente matemática e física), uma voltada para concursos militares, outra com enfoque em vestibulares de instituições públicas, e uma turma específica para ingresso em faculdades de medicina.

Justamente por sua característica de buscar excelência no desempenho dos alunos, a concorrência mais direta do Elite ocorre na esfera dos cursos pré-vestibulares altamente especializados, onde a aprovação nos vestibulares mais concorridos é o maior fator de renome. 


\section{Público-alvo}

Cada unidade define seu público-alvo de maneira independente, levando em consideração fatores como a localização geográfica e a concorrência local. O preço praticado nas mensalidades também é um importante componente na definição desse público. Assim, a maioria das unidades utiliza uma precificação voltada para alunos pertencentes à classe $\mathrm{B}$; a qualidade do curso atrai também integrantes da classe $\mathrm{A}$, como público-alvo secundário. Por não haver uma padronização nos preços, outras unidades, por sua vez, assumem um posicionamento de exclusividade na classe A, cobrando valores mais elevados. Por fim, o Rio de Janeiro representa um caso à parte, pois, apesar de o foco das operações na cidade ser a classe B, a existência de diversas unidades espalhadas pela região permite que as classes A e C também sejam atendidas de maneira secundária.

Além disso, por características da concorrência e dos concursos locais, cada unidade define também sua força em termos de conteúdo e turmas disponíveis. Existem, por exemplo, unidades com muita força na área de ciências exatas e turmas com foco em concursos militares, como também unidades fortes na área de ciências biológicas e turmas voltadas para medicina, ou ainda com grande força em ciências exatas, mas com foco em medicina.

\section{Estrutura operacional}

Apesar de cada unidade ter sua administração de maneira independente, e de não haver uma padronização formal nas operações, algumas linhas gerais são seguidas por todos os componentes do sistema. Assim, as atividades de marketing e operação direta - como formação e divulgação de novas turmas e desenvolvimento do conteúdo didático e das aulas - são a base do funcionamento de cada curso, ao passo que as tarefas de operação indireta e administrativa - preparação de materiais complementares, controles financeiros, seleção de professores etc. - são executadas de acordo com a alocação dos recursos (tempo, dinheiro, mão de obra etc.) não utilizados pelas atividades principais.

Além disso, a partir do aprendizado decorrente dos anos e do cuidado com a qualidade do serviço prestado, os seguintes preceitos básicos são seguidos por todas as unidades:

- Equipe de professores formada após um cuidadoso processo de seleção.

- Monitoria formada por alunos universitários de destaque, oriundos de instituições de renome (públicas ou particulares).

- Atendimento personalizado, possibilitando ao aluno um completo acesso aos professores e demais profissionais envolvidos.

- Simulados semanais, desde o início do curso - simulação das condições de prova dos vestibulares, onde os alunos testam seus conhecimentos e treinam para as provas efetivas.

Ambiente de estudo agradável - salas de estudos com temperatura controlada, iluminação propícia e móveis confortáveis.

Porém, apesar destes pilares comuns, as minúcias de cada processo são de responsabilidade de cada estabelecimento. Assim, não existem normas rígidas para implementar tais procedimentos, apenas orientações gerais, utilizadas de acordo com a necessidade. A seleção de professores é um exemplo dessa política. O processo geral é composto de duas fases - prova para testar os conhecimentos teóricos e avaliação da didática em sala de aula. Entretanto, algumas unidades usam somente uma dessas etapas, enquanto outras aplicam critérios adicionais (como reconhecimento no mercado) para complementar a seleção. 


\title{
Diferencial
}

O Elite busca seu diferencial na alta performance de seus alunos, refletida pelos elevados níveis de qualidade e exigência apresentados. Esse nível de exigência serve até mesmo para segmentar o público-alvo, uma vez que a intenção é contar com os melhores estudantes, em busca de aprovação nos concursos vestibulares com maior grau de dificuldade do país. Por conta disso, as principais fontes de divulgação da empresa são a aprovação constante nos vestibulares citados - comunicada de maneira ostensiva nas regiões com presença do Sistema Elite, por meio principalmente de mídia impressa e outdoors - e a indicação de alunos satisfeitos com os resultados obtidos no curso. Esses alunos, num primeiro momento, oferecem grande resistência ao método de ensino utilizado, por causa do seu grau de exigência. Entretanto, uma vez assimilada a metodologia e, principalmente, observados os resultados, os estudantes tornam-se fiéis defensores da marca, constituindo uma das ferramentas de propaganda mais importantes da empresa.

\section{Dilema}

Por conta da situação em que o Sistema Elite de Ensino se encontra, Alberto perdeu algumas horas de sono na noite anterior à reunião com seus sócios. Estavam todos em Porto Alegre para tentar definir os rumos da empresa. Pela manhã, com os quatro reunidos no local marcado, Alberto iniciou a discussão

\begin{abstract}
"Achei importante marcar esta reunião para chegarmos a um consenso sobre o crescimento da nossa empresa. Meu envolvimento na abertura da filial de Ipatinga me fez perceber que estamos perdendo oportunidades interessantes em regiões ainda não exploradas, e com isso perdendo espaço para a concorrência".
\end{abstract}

Estevão, ao ouvir a colocação, argumentou:

"Eu concordo que estamos perdendo oportunidades, Alberto, mas não podemos ir atrás delas sem um fortalecimento interno. Você sabe que não temos estrutura pra esse tipo de crescimento. Hoje, cada unidade faz o que quer, é uma bagunça generalizada. Enquanto não tivermos uma padronização nas atividades, as unidades não vão conseguir crescer sozinhas".

Giordano, discordando do sócio, continuou:

"O problema das unidades menores não é a padronização, mas sim a falta de apoio das maiores. Se houver este apoio, a padronização é secundária. Até porque cada região tem características muito diferentes; não podemos enrijecer os processos de modo que o curso fique pasteurizado, sem levar em conta as nuances de cada praça".

Estevão replicou:

"Giordano, é justamente por isso que não existe suporte para as filiais menores. Como não existem procedimentos uniformes, cada unidade precisa resolver seus problemas de forma isolada. Enquanto não criarmos um sistema de diretrizes bem estruturado, não adianta pensar em apoio para as filiais existentes, quanto mais para novas aberturas!"

Alberto, que ouvia a interação entre dos dois, interveio:

"O problema é frearmos nosso crescimento por conta de questões burocráticas. Hoje, estamos presos a um crescimento vegetativo, por necessidade do envolvimento de um dos sócios em qualquer projeto. Com esta administração centralizada, logo atingiremos nosso limite, pois cada um de nós já dedica tempo demais às unidades existentes. Talvez uma solução seja um crescimento mais estruturado, na forma de uma franquia". 
Estevão continuou defendendo seu ponto de vista:

"Mesmo se pensarmos no modelo de franquia, ainda há a necessidade de uma padronização, talvez até de forma mais intensa. Não podemos simplesmente ceder nossa marca para algum curso em um lugar qualquer, sem termos garantias de que o serviço será oferecido com a qualidade inerente ao nosso nome".

Alberto contra-argumentou:

"Concordo contigo, Estevão. Porém, temos outro problema. Esta uniformidade nacional exige tempo, recursos humanos e financeiros de que não dispomos no momento. Nós sabemos que nenhum de nós pode se dedicar exclusivamente a isso, e que nosso pessoal de apoio nas unidades já é muito reduzido. Não podemos deixar nosso crescimento refém desta situação!"

Nicolau, que ainda não se havia manifestado, decidiu expor sua opinião:

"Pra esse problema, temos uma solução viável. Todos nós já fomos abordados por investidores externos, querendo se associar à nossa empresa. Se negociarmos com um destes investidores potenciais, teremos a segurança financeira para cuidar da empresa como um todo, e podemos nos concentrar na integração nacional e na padronização".

Giordano ponderou a ideia:

"Esta é uma alternativa viável, realmente. Este fôlego financeiro pode nos ajudar a concentrar esforços no auxílio às novas unidades. Porém, teremos outro tipo de trabalho, para estruturar um plano de crescimento por meio da abertura de novas filiais".

Nicolau fez uma nova intervenção, dessa vez em outra direção:

"Em relação a isso, existe uma outra alternativa interessante. Não precisamos expandir o número de unidades. O modelo de negócio mais rentável é o licenciamento de material didático. Se mantivermos nossa marca forte nas cidades onde já atuamos, podemos utilizar esta vantagem competitiva para alavancar a venda do material com a marca Elite, sem nos preocuparmos com as dificuldade operacionais ou o alto investimento exigido para a criação de novas filiais em outras regiões".

Interromper o crescimento físico, em benefício do foco no licenciamento de material didático? Alberto não havia pensado nesta possibilidade! Aos seus olhos, o dilema apresentava-se muito maior que o imaginado anteriormente. Cada sócio possuía um posicionamento, e atingir um consenso seria tarefa complicada. Entretanto, alguma decisão precisa ser tomada. A cada dia de crescimento adiado, aumenta a oportunidade da concorrência tomar o mercado conquistado pelo Elite. Independentemente do tempo necessário, no final da reunião alguma estratégia de crescimento deve ser adotada. 


\title{
Notas de Ensino
}

\section{Resumo}

O Sistema Elite de Ensino atua no mercado brasileiro de cursos pré-vestibular, com foco na preparação para os exames mais concorridos do país. Fundado em 1998 por quatro sócios, está presente em dez cidades pelo Brasil. Após um período de expansão desorganizada, onde o desenvolvimento individual das unidades foi privilegiado em detrimento da padronização e integração entre elas, a empresa teve o seu crescimento refreado por conta da falta de concordância entre os proprietários em relação aos caminhos que deveriam ser adotados para tal crescimento. O presente caso de ensino tem como objetivo colocar o aluno no papel de um dos sócios do Sistema Elite de Ensino, que precisa atingir um consenso com os demais proprietários para desenvolver a estratégia de expansão da organização para os próximos anos. Espera-se que o aluno pondere qual a direção mais apropriada para o desenvolvimento de uma empresa de serviços. Pode ser utilizado em aulas sobre marketing de serviços, estratégia de marketing ou empreendedorismo, em cursos de extensão ou pósgraduação lato sensu e stricto sensu.

Palavras-chave: caso de ensino; marketing de serviços; estratégia de crescimento; marketing estratégico; empreendedorismo.

\begin{abstract}
The Sistema Elite de Ensino operates in the Brazilian college preparation courses market, focusing on preparation to the most disputed examinations in the country. Founded in 1998 by four partners, Elite operates in ten Brazilian cities. After a period of disorganized expansion, when the individual development of the units was given priority in detriment of standardization and integration among them, the organization's growth was restricted due to a lack of agreement among its owners concerning the paths that should be followed to pursue this growth. The objective of this teaching case is to put the student in the role of one of the owners of Sistema Elite de Ensino in order to reach a consensus with the other owners to develop the firm's growth strategy for the following years. The student is expected to think about the most appropriate way for a service company to develop. This teaching case can be used in Services Marketing, Marketing Strategy or Entrepreneurship classes, in lato sensu and stricto sensu graduation courses.
\end{abstract}

Key words: teaching case; services marketing; growth strategy; marketing strategy; entrepreneurship.

\section{Objetivos de aprendizagem}

Espera-se que os alunos, no final da leitura, sejam capazes de atingir os seguintes objetivos:

- Ponderar, com base nos prós e contras de cada alternativa, qual a melhor estratégia para o crescimento da empresa.

- Exercitar, a partir de informações provenientes da empresa e do mercado, a análise de estratégias distintas dentro de uma empresa de serviços.

- Identificar e aplicar os conceitos específicos relativos ao marketing de serviços, como padronização, qualidade do serviço e evidências físicas.

\section{Utilização recomendada}

Este caso de ensino foi elaborado para ser utilizado em cursos de extensão ou pós-graduação lato sensu e stricto sensu. Pode ser empregado, por exemplo, em aulas sobre marketing de serviços, 
estratégia de marketing ou empreendedorismo, nas disciplinas de Marketing, Marketing de Serviços ou Estratégia Empresarial.

\section{Obtenção dos dados}

Os dados para a elaboração deste caso de ensino foram obtidos por meio de entrevistas com os sócios do Sistema Elite de Ensino.

\section{Questões para discussão}

1. Se você fosse um dos sócios, que atitude tomaria em relação ao crescimento da empresa? É necessário que haja uma padronização, ou a independência operacional é a alternativa mais indicada para o sucesso das unidades?

2. Em âmbito nacional, como deve ser conduzido o desenvolvimento da empresa? Deve-se trabalhar com uma administração centralizada nos sócios, ou a ampliação do sistema pode ser baseada em franquias?

3. Se você fosse um investidor, qual seria sua posição em relação ao futuro da organização? Buscaria a expansão da marca por meio da abertura de novas unidades, ou concentraria os esforços na venda de material didático?

4. A criação de um sistema integrado deve abarcar as unidades com marca própria, ou essas devem ser excluídas do grupo? Se mantidas, como deve ser administrada a marca nas referidas unidades? Precisa haver uma uniformidade, ou as marcas próprias devem ser conservadas por seu reconhecimento?

5. Que procedimentos devem ser adotados para garantir a qualidade do serviço dentro da organização?

6. Faça uma análise estratégica do Sistema Elite de Ensino, considerando suas forças, fraquezas, ameaças e oportunidades. Que decisões devem ser tomadas a partir desta análise?

\section{Técnicas didático-pedagógicas}

Este caso de ensino foi desenvolvido para leitura prévia dos alunos. Em sala de aula, as atividades podem ser conduzidas das seguintes formas:

1. Divisão dos estudantes em dois ou mais grupos, cada qual defendendo um ponto de vista diferente (padronização x autonomia, administração centralizada x franquia, crescimento físico $\mathrm{x}$ venda de material didático), sendo o professor o mediador/juiz do processo.

2. Dois grupos, com posições diferentes, apresentam as vantagens e desvantagens para um terceiro grupo, formado por investidores. Estes, por sua vez, também devem convencer os empresários sobre a forma que consideram a melhor para o crescimento da organização.

\section{Breve revisão da literatura}

Antes da análise do caso em si, alguns pontos em relação à fundamentação teórica devem ser observados. O primeiro deles é a natureza peculiar de uma empresa prestadora de serviços. Shostack (1977) estabelece as bases de distinção entre bens e serviços por meio de uma característica primordial: a intangibilidade inerente aos últimos. A partir desta característica, Shostack (1977) apresenta um contínuo em que a empresa deve ser alocada de acordo com o grau de tangibilidade presente em sua oferta. Nas palavras da própria autora, serviços de educação encontram-se próximos ao extremo de dominância intangível. 
Além da intangibilidade, outras três características estão presentes nos serviços: inseparabilidade entre produção e consumo, variabilidade e perecibilidade (Kotler \& Keller, 2006). Por conta de tais características, a administração de serviços também é tratada de forma diferente em relação a bens físicos. Por exemplo, além do composto de marketing clássico utilizado na manufatura (produto, preço, promoção e distribuição), o gerenciamento de serviços acrescenta outras quatro dimensões estratégicas: processos, produtividade e qualidade, pessoas e evidências físicas (Lovelock \& Wright, 2001).

Outro ponto importante diz respeito ao tipo de crescimento que a empresa deve empreender. Existem diversos modelos de estratégia de crescimento empresarial: um dos mais utilizados é a matriz de Ansoff. Nesse modelo, o desenvolvimento da empresa é baseado em duas dimensões: os produtos que a organização oferece e os mercados que ela atinge. Por conta disso, o modelo também é chamado de matriz produtos-mercados (Ansoff, 1990). A partir da combinação entre as dimensões, é possível identificar quatro tipos de crescimento: penetração de mercado (produtos atuais x mercados atuais); desenvolvimento de mercado (produtos atuais $\mathrm{x}$ mercados novos); desenvolvimento de produto (produtos novos x mercados atuais); e diversificação (produtos novos x mercados novos).

\section{Análise do caso}

Como subsídio para a aplicação desse caso de ensino, os autores sugerem a análise de cada questão nos próximos parágrafos.

Questão 1. Apesar de os consumidores normalmente buscarem alguma customização nos serviços, a padronização operacional é fundamental para reduzir a variabilidade inerente a esse tipo de oferta. Dessa forma, há maior controle da qualidade e da produtividade dos serviços prestados (Lovelock \& Wright, 2001). Além disso, quanto mais intangível for a oferta, mais o serviço depende de evidências físicas para comunicar suas características e qualidade para o consumidor, uma vez que tais evidências possuem um impacto significativo na percepção do cliente (Shostack, 1977). Assim, a padronização - tanto das operações quanto das evidências físicas - aparece como ponto fundamental na estratégia de crescimento do Sistema Elite de Ensino. A organização, na ocasião, não possui uma identidade nacional única, o que dificulta a identificação dos clientes em relação às diversas unidades espalhadas pelo Brasil. Então, o primeiro passo para estruturar o crescimento da empresa seria promover a padronização dos processos-chave e da identidade visual da firma, até mesmo como subsídio para apoiar as unidades novas ou que ainda não possuem grande reconhecimento no mercado. Com base nessa estruturação, as futuras unidades do Elite terão a infraestrutura básica para iniciar suas operações, buscando então atender às demandas específicas de cada localidade.

Deve-se ressaltar, entretanto, que a padronização operacional em um grau demasiado poderia prejudicar a flexibilidade necessária às unidades do sistema, uma vez que, para o tipo de oferta do Elite, cada região atendida tem demandas bastante específicas. Da mesma forma, em um mercado com concorrentes muito heterogêneos e públicos bem diferentes, poderia haver um engessamento que impossibilitaria reações rápidas às modificações ambientais. Por isso, o mais indicado seria buscar uma padronização das operações gerais, deixando alguma margem para que cada unidade trabalhe sua adaptação ao mercado da melhor forma. Na questão do material didático, por exemplo, o aconselhável seria utilizar o mesmo conteúdo básico para cada tipo de curso em todo o sistema, adaptando somente os assuntos peculiares a cada região - história, geografia, geopolítica etc.

Uma vez alcançado esse nível de padronização operacional e identidade, a primeira estratégia de crescimento a ser adotada seria a penetração de mercado, com foco voltado para o fortalecimento da marca nos mercados já existentes, por meio dos produtos que a empresa já oferece - agora, porém, de maneira mais estruturada. A seguir, com as operações mais robustas e imagem fortalecida, o próximo passo poderia ser buscar o desenvolvimento de mercado, levando os produtos existentes para regiões onde o Elite ainda não atua.

Questão 2. Em relação ao desenvolvimento centralizado ou por meio de franquias, novamente a questão da padronização torna-se relevante. Como não existe uma identidade nacional para o sistema, seja em termos de marca ou de evidências físicas, é mais difícil implantar e controlar novas unidades 
pela abertura de franquias, ainda mais considerando o alto nível de qualidade exigido nos serviços prestados pelo Elite. Assim, nesse momento seria aconselhável o crescimento centralizado, aliado ao esforço de padronização nacional.

Questão 3. Da mesma forma que na questão anterior, a falta de padronização é um empecilho para a expansão por meio da venda de material didático, uma vez que o sucesso dessa empreitada depende da associação do material a uma marca forte. Por isso, o indicado seria consolidar a marca por meio das unidades físicas dispostas em território nacional, para então considerar a expansão por meio de outro produto dentro dos mercados em que a organização já atua (estratégia de desenvolvimento de produto) ou em novos mercados (estratégia de diversificação).

Questão 4. Assim como as evidências físicas, a marca associada a um serviço tem papel fundamental no posicionamento da empresa, tanto para definir sua diferenciação perante a concorrência quanto para assegurar ao consumidor a qualidade do serviço oferecido (Lovelock \& Wright, 2001). Por conta disso, a marca do Sistema Elite de Ensino deve ser trabalhada de maneira uniforme por todas as unidades, proporcionando que a imagem já consolidada pelas filiais estabelecidas auxilie no crescimento e reconhecimento de novas unidades. O ideal, então, seria abarcar as unidades que utilizam marca própria - visto que estas possuem uma imagem sólida nos mercados em que atuam. Nesse caso, é aconselhável que a migração para a marca única seja gradual - primeiro, com a introdução da marca Elite em conjunto com a marca própria; após um período de utilização da marca mista para que os consumidores associem a marca antiga à nova, a primeira deveria ser retirada gradualmente até que a identificação da unidade siga somente o padrão do Sistema Elite de Ensino.

Questão 5. A padronização é uma das formas mais usuais de garantir a qualidade do serviço prestado. A uniformização dos processos faz com que a prestação dos serviços aconteça de maneira mais homogênea, diminuindo a insegurança do cliente. Além disso, a existência de elementos comuns - como identidade visual e material didático - gera as evidências físicas necessárias para garantir o reconhecimento da marca e atestar a qualidade do seu serviço. No caso do Sistema Elite de Ensino, a busca pela padronização seria o procedimento mais evidente a ser adotado. Além disso, outros fatores citados por Kotler e Keller (2006) seriam indicados nesta situação, como o comprometimento da alta gerência, a existência de padrões rigorosos e a implantação de sistemas de monitoramento.

Questão 6. Uma ferramenta de planejamento estratégico muito importante é a análise SWOT, utilizada para monitorar tanto o ambiente interno quanto o externo da empresa (Kotler \& Keller, 2006). Essa análise utiliza as forças e fraquezas da organização e as oportunidades e ameaças próprias de seu mercado de atuação para orientar os rumos do crescimento da empresa. Em linhas gerais, a Tabela 2 apresenta os pontos principais da análise SWOT do Elite, sendo que outros podem surgir das discussões em sala de aula.

Tabela 2

\section{Análise SWOT do Sistema Elite de Ensino}

\begin{tabular}{|c|c|}
\hline Forças & Fraquezas \\
\hline $\begin{array}{l}\text { Reconhecimento do curso como sendo de alta } \\
\text { qualidade nas áreas de atuação }\end{array}$ & $\begin{array}{l}\text { Falta de padronização entre as unidades, mesmo no } \\
\text { que diz respeito à marca }\end{array}$ \\
\hline \multirow{4}{*}{$\begin{array}{l}\text { Unidades com poder de adaptação a demandas locais e } \\
\text { regionais } \\
\text { Os alunos e ex-alunos atuam como defensores da } \\
\text { marca }\end{array}$} & Estagnação do crescimento por razões burocráticas \\
\hline & Ausência de suporte por parte das unidades maiores \\
\hline & para o desenvolvimento do sistema \\
\hline & Não existe uma identidade nacional do sistema \\
\hline Oportunidades & Ameaças \\
\hline $\begin{array}{l}\text { Abertura de novas unidades em regiões carentes por } \\
\text { cursos de alto nível }\end{array}$ & $\begin{array}{l}\text { Mercado favorável à proliferação de cursos } \\
\text { preparatórios com menor nível de exigência }\end{array}$ \\
\hline Expansão do sistema por meio de franquias & Concorrência nacional com redes de ensino mais \\
\hline Comercialização de material didático & estruturadas e com muito reconhecimento no mercado \\
\hline
\end{tabular}




\section{Bibliografia Recomendada}

Como suporte teórico para aplicação deste caso de ensino, podem ser utilizados livros de marketing, marketing de serviços e estratégia empresarial, como os citados no referencial teórico:

Ansoff, H. I. (1990). A nova estratégia empresarial. São Paulo: Atlas.

Kotler, P., \& Keller, K. L. (2006). Administração de marketing (12a ed.). São Paulo: Pearson Prentice Hall.

Lovelock, C., \& Wright, L. (2001). Serviços: marketing e gestão. São Paulo: Saraiva.

Outras leituras mais específicas também podem ser utilizadas, no caso de temas como marketing de serviços, empreeendedorismo e franquia respectivamente:

Bhide, A. (2002). As perguntas que todo empreendedor deve responder. In Harvard Business Review, Empreendedorismo e estratégia (pp. 9-34). Rio de Janeiro: Campus.

Plá, D. (2001). Tudo sobre franchising. Rio de Janeiro: SENAC

Shostack, G. L. (1977). Breaking free from product marketing. Journal of Marketing, 41(2), 73-80. doi: $10.2307 / 1250637$

\section{Agradecimentos}

O presente trabalho foi realizado com o apoio do Conselho Nacional de Desenvolvimento Científico e Tecnológico (CNPq) Brasil.

\section{Referências}

Ansoff, H. I. (1990). A nova estratégia empresarial. São Paulo: Atlas.

Kotler, P., \& Keller, K. L. (2006). Administração de marketing (12a ed.). São Paulo: Pearson Prentice Hall.

Lovelock, C., \& Wright, L. (2001). Serviços: marketing e gestão. São Paulo: Saraiva.

Shostack, G. L. (1977). Breaking free from product marketing. Journal of Marketing, 41(2), 73-80. doi: $10.2307 / 1250637$ 